\title{
Berberine Protects against Hydrogen Peroxide-Induced Oxidative Damage in PC12 Cells through Activation of ERK1/2 Pathway
}

Liu $L^{1}$, Zeng $Z^{1}$, Gaur $U^{1}$, Fang $J^{1}$, Little $P J^{2}$ and Zheng $\mathbf{W}^{1^{\star}}$

${ }^{1}$ Faculty of Health Sciences, University of Macau, Taipa, Macau, China

${ }^{2}$ School of Pharmacy, Pharmacy Australia Centre of Excellence (PACE), The University of Queensland, Australia

*Corresponding author: Zheng W, Faculty of Health Sciences, University of Macau, Taipa, Macau, China, Tel: +853-88224919; E-mail: wenhuazheng@umac.mo

Received date: April 24, 2017; Accepted date: May 02, 2017; Published date: May 09, 2017

Copyright: ( 2017 Liu L, et al. This is an open-access article distributed under the terms of the Creative Commons Attribution License, which permits unrestricted use, distribution, and reproduction in any medium, provided the original author and source are credited.

\begin{abstract}
Oxidative stress is a much-recognized phenomenon linked with the progression of Neurodegenerative Diseases (NDs) due to imbalances in redox homeostasis. Increasing evidence indicates that excessive Reactive Oxygen Species (ROS), impairing the physiological functions of neurons via inducing cell apoptosis, is the main cause of NDs. The drug candidates are required that can effectively protect neurons from oxidative stress insult to slow down the process of neurodegenerative diseases. In present study, we investigated the protective effect and the underlying mechanisms of berberine (BBR, an isoquinoline alkaloid isolated from the herb Rhizoma coptidis, against oxidative damage in PC12 cells. It was found that BBR was able to suppress hydrogen peroxide $\left(\mathrm{H}_{2} \mathrm{O}_{2}\right)$ induced cell death in PC12 cells. Flow cytometry revealed that BBR significantly reduced the apoptosis of PC12 cells exposed to $\mathrm{H}_{2} \mathrm{O}_{2}$. Western blot analysis displayed that BBR stimulated the extracellular regulated ERK1/2 survival signaling, while application of PC12 cells with ERK1/2 pathway inhibitor PD98059 blocked the neuroprotective effect of BBR. These results together indicated that BBR is a potential protectant, and it protects PC12 cells against $\mathrm{H}_{2} \mathrm{O}_{2}$ toxicity through activated the ERK1/2 pathway.
\end{abstract}

Keywords: Berberine; Degenerative disease; PC12 cells; ERK1/2

\section{Introduction}

Neurodegenerative diseases (ND), such as Alzheimer's (AD) and Parkinson's disease (PD), are chronic degenerative pathologies of the Central Nervous System (CNS). NDs are characterized by progressive loss of specific neurons which further leads to a decline in brain functions $[1,2]$. Despite the fact that pathologies have different clinical features, there are some common hallmarks, such as synaptic dysfunctioning, oxidative stress, and inflammation [3]. The NDs are caused by an enhancement of ROS production via mitochondria and NADPH oxidase (NOX), which seems to account for tissue injury and neurodegeneration $[4,5]$. Nowadays, NDs are chronic and incurable conditions, and the disabling effects may continue for years or even decades representing an enormous disease load, regarding human suffering and economic cost [6,7]. In neuronal cells, the over production of ROS is considered as one of the risk factors for NDs $[8,9]$. Disruption of redox homeostasis is a key phenotype of many pathological conditions. Hydrogen peroxide $\left(\mathrm{H}_{2} \mathrm{O}_{2}\right)$, the main source of ROS, can cause cell membrane injury as well as lipid peroxidation and DNA damage in variety cells. However, antioxidants were able to protect cells against $\mathrm{H}_{2} \mathrm{O}_{2}$-induced cell death via reducing $\mathrm{ROS}$ production [10].

Recently, a number of natural medicinal plants have been tested for their therapeutic properties, revealing that the raw extracts or isolated pure compounds from them had more effective properties than the whole plant itself for the treatment of ND and other disease $[11,12]$. In the last decade, more and more attention has been paid to the antioxidant activities of natural products and compounds isolated from plants which usually have higher efficacy and lower side effects. Berberine (BBR) is an isoquinoline alkaloid (5,6- dihydrodibenzoquinolizinium derivative), which belongs to the structural class of protoberberines and is extracted from several medicinal herbs, particularly in the genus berberis [8]. Previous studies have shown that BBR has abundant pharmacological activities, including antioxidant, anticancer, anti-inflammation, antidepressant, neuroprotection, hepatoprotection, cerebroprotection and cardioprotection $[13,14]$. In recent years, BBR has been reported to exert beneficial effects in neurodegenerative and neuropsychiatric disorders because of its dual antioxidant and anti-apoptotic activities [15-18].

It has been found that BBR-mediated neuroprotection against neuronal apoptosis is regulated by several pathways including Akt/ GSK3 $\beta$, ERK1/2, AMPK, Nrf2/HO-1 survival/apoptotic signaling pathway as well as JNK and Caspase-3 activity inhibition $[19,20]$. Different studies have shown that BBR inhibited superoxide anions and had radical scavenging activity against the highly reactive hydroxyl radicals, while the mechanisms and signaling pathways involved in its antioxidant effects are still not very clear. The rat pheochromocytoma PC12 cells are useful neuronal models for the study of neuronal degenative disorders such as Alzheimer's disease, and also widely used to investigate free ROS biochemical pathways involved in cell death and neuroprotection [21]. Hence, this cell line is a suitable model for studyi-ng oxidative stress-induced neuronal injury.

In present study, we discovered that BBR was able to protect PC12 cells against $\mathrm{H}_{2} \mathrm{O}_{2}$-induced oxidative damage via inhibiting the apoptosis. We also displayed that the neuroprotective effect of BBR is mediated through the ERK1/2 pathway. These findings suggest that BBR is able to protect PC12 cells against $\mathrm{H}_{2} \mathrm{O}_{2}$ injury by the MAPK pathway and further support that the BBR administration might be a possible therapeutic approach for the treatment of $\mathrm{AD}$. 


\section{Materials and Methods}

\section{Materials}

Dimethyl Sulfoxide (DMSO), poly-L-lysine and bovine serum albumin were purchased from Sigma (St. Louis, MO, USA). Fetal Bovine Serum (FBS), Penicillin-Streptomycin (PS), DMEM and trypsin were obtained from Invitrogen (Carlsbad, USA). Methyl Thiazolyl Tetrazolium (MTT) was got from Molecular Probes (Eugene, OR, USA). Annexin V-FITC/PI Apoptosis Detection Kit was purchased from BD Biosciences (San Diego, CA, USA). Anti- $\beta$-actin and phospho-ERK1/2 antibodies were obtained from Cell Signaling Technology (Woburn, USA). ERK1/2 inhibitor PD98059 was obtained from Selleckchem.

\section{Cell culture and treatment}

The rat pheochromocytoma PC12 cell, NIH clone, was kindly provided by Dr. Gordon Guroff (National Institute of Child Health and Human Development, National Institutes of Health, Bethesda, MD, USA). Cells were cultured in Dulbecco's Modified Eagle Medium supplemented with $10 \%$ heat-inactivated horse serum, $5 \%$ Fetal Bovine Serum (FBS) and antibiotics (100 U/mL penicillin; $100 \mu \mathrm{g} / \mathrm{mL}$ streptomycin) as previously described $[22,23]$. Cells were incubated at $37^{\circ} \mathrm{C}$ with $5 \% \mathrm{CO}_{2}$ humidified atmosphere. All experiments were carried out $24 \mathrm{~h}$ after the cells were seeded. For the protection assay, PC12 cells were pre-treated with BBR for $2 \mathrm{~h}$, and then treated with $\mathrm{H}_{2} \mathrm{O}_{2}$ for $24 \mathrm{~h}$ in all experiments. In addition, BBR was removed from the cell culture medium before $\mathrm{H}_{2} \mathrm{O}_{2}$ exposure.

\section{MTT assay}

Mitochondrial activity, a measure of cell death, was measured by the MTT assay as previously described [24]. Briefly, PC12 cells were seeded in 96-well plates at a density of $\times 10^{3}$ cells/well. After serum starvation, the cultures were incubated with different reagents for $24 \mathrm{~h}$ Thereafter, MTT $(0.5 \mathrm{mg} / \mathrm{mL})$ was added to each well for an additional $4 \mathrm{~h}$. Subsequently, medium was removed, and DMSO $(100 \mu \mathrm{l})$ was added to each well to solubilize the formazan salt. Absorbance was measured at $490 \mathrm{~nm}$ by Infinite M200 PRO Multimode Microplate (Tecan, Switzerland). The relative cell viability was presented as a percentage compared with the control group.

\section{Apoptosis of PC12 cells measured by flow-cytometry}

The PC12 cells after treatment were analyzed by flow cytometer Briefly, the PC12 cells were collected by centrifugation (2000 rpm for 5 $\mathrm{min}$ ) and washed with PBS for two times. Cells were suspended in 400 $\mu \mathrm{l}$ of $1 \mathrm{X}$ Binding Buffer. $5 \mu \mathrm{l}$ Annexin V-EGFP mix was added in each sample followed by the addition of $10 \mu$ Propidium Iodide; mixed and kept away from light at room temperature for $20 \mathrm{~min}$. Data acquisition and analysis were performed using BD C Sample plus.

\section{Western blot analysis}

The western blotting in this study was carried out as described previously [25]. Briefly, cells after different treatment were washed once with ice-cold PBS, then lysed in RIPA buffer $(10 \mathrm{mM}$ Tris- $\mathrm{HCl}$, $\mathrm{pH}$ 7.4, $5 \mathrm{mM}$ EDTA, $1 \mathrm{mM}$ phenylmethylsulfonyl fluoride, $20 \mu \mathrm{g} / \mathrm{ml}$ leupeptin, $0.1 \%$ aprotinin, $1 \mathrm{mM}$ iodoacetamide, $200 \mu \mathrm{g} / \mathrm{ml}$ bacitracin, $20 \mu \mathrm{g} / \mathrm{ml}$ soybean trypsin inhibitor, $10 \mathrm{mM} \mathrm{NaCl}$ and $0.25 \%$ Triton $\mathrm{X}-100)$ for $15 \mathrm{~min}$ on ice. Protein concentrations were measured by
BCA protein assay kit (Bio-Rad, Hercules, CA, USA) following the manufacturer's instructions. For western blotting, samples $(20 \mu \mathrm{g}$ protein/lane) were separated by SDS-PAGE gel with a pre-stained protein ladder $(5 \mu \mathrm{l})$ as a molecular weight marker, and then transferred to PVDF membranes. The p-ERK1/2 was determined by phospho-specific antibody while $\beta$-actin was used as a loading control. Immuno-reactive bands were visualized by ECL kit according to the manufacturer's instructions. The intensity of band was quantified using Image J software. The experiments were repeated for 3 times by using independent cultures.

\section{Statistical analysis}

Statistical analysis and data handling were performed using SPSS version 16.0. All experiments were repeated for 3 times. All the data for continuous variables were expressed as the mean \pm standard deviation $(\mathrm{X} \pm \mathrm{SD})$ along with ranges. Statistical analysis was performed using one-way ANOVA followed by Tukey's multiple comparison. The null hypothesis was rejected at $\mathrm{P}<0.05$.

\section{Results}

\section{BBR attenuated the decrease in cell viability induced by $\mathrm{H}_{2} \mathrm{O}_{2}$ in $\mathrm{PC1} 2$ cells}

To calculate the cytotoxicity of $\mathrm{H}_{2} \mathrm{O}_{2}, \mathrm{PC} 12$ cells were incubated with different concentrations of $\mathrm{H}_{2} \mathrm{O}_{2}$ for $24 \mathrm{~h}$ and the cell viability was measured by MTT assay. As shown in Figure $1, \mathrm{H}_{2} \mathrm{O}_{2}$ treatment for 24 $\mathrm{h}$ significantly decreased the cell viability of $\mathrm{PC} 12$ cells in a concentration-dependent manner. $\mathrm{H}_{2} \mathrm{O}_{2}$ at $200 \mu \mathrm{M}$ caused about $20 \%$ loss in cell viability, thus this concentration of $\mathrm{H}_{2} \mathrm{O}_{2}$ was used in the coming experiments to produce the cell insult and to measure neuroprotection. To investigate the cytotoxicity of BBR, PC12 cells were treated with different concentrations of BBR for $24 \mathrm{~h}$, and the cytotoxicity was measured by MTT assay. As shown in Figure 2, BBR did not show any cytotoxicity between 0.315 and $5 \mu \mathrm{M}$, and these concentrations were used in further experiments. To examine the protective effects of BBR, PC12 cells were incubated with BBR for $2 \mathrm{~h}$ and then exposed to $\mathrm{H}_{2} \mathrm{O}_{2}$ for $24 \mathrm{~h}$. The result form MTT assay revealed that pre-treatment with 1 or $2 \mu \mathrm{M}$ of $\mathrm{BBR}$ significantly attenuated $\mathrm{H}_{2} \mathrm{O}_{2}$-induced cell viability loss in a concentrationdependent manner.

\section{Protective effect of $\mathrm{BBR}$ on $\mathrm{H}_{2} \mathrm{O}_{2}$-induced apoptosis in the PC12 cells}

It was reported that cell death caused by $\mathrm{H}_{2} \mathrm{O}_{2}$ was mainly mediated by apoptosis [26] and BBR was able to protect cells from apoptosis in various cell types [20,27]. We therefore investigated whether $\mathrm{BBR}$ could reduce the cell apoptosis caused by $\mathrm{H}_{2} \mathrm{O}_{2}$ in $\mathrm{PC} 12$ cells. Cell apoptosis was tested by flow cytometry, and the data indicated that $\mathrm{H}_{2} \mathrm{O}_{2}$ exposure markedly increased apoptosis in $\mathrm{PC} 12$ cells, while BBR pre-treatment significantly reduced the apoptosis caused by $\mathrm{H}_{2} \mathrm{O}_{2}$ (Figure 2). 

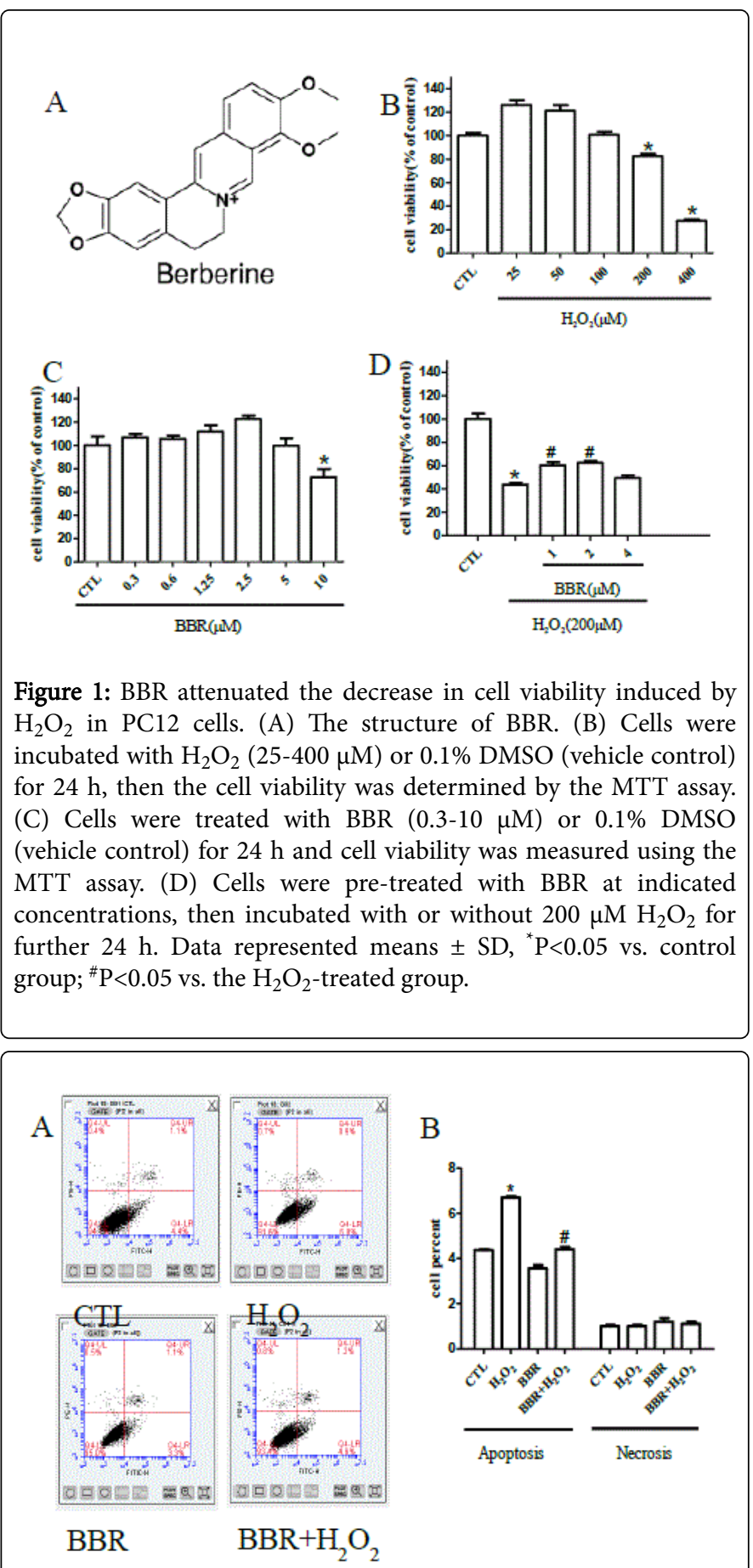

Figure 2: Protective effect of BBR on $\mathrm{H}_{2} \mathrm{O}_{2}$-induced apoptosis in the PC12 cells. (A) Photographs of representative cultures measured by flow cytometry. (B) Quantitative analysis of (A). The data were represented as the mean \pm standard deviation of three independent experiments. ${ }^{*} \mathrm{P}<0.05$ vs. control group; ${ }^{\#} \mathrm{P}<0.05$ vs. the $\mathrm{H}_{2} \mathrm{O}_{2}$ treated group.

\section{BBR stimulated the ERK1/2 signaling pathway in PC12 cells}

ERK1/2 pathway phosphorylation is a key biochemical event responsible for cell survival and apoptosis. BBR was able to activate ERK1/2 signaling in mice as reported earlier [28]. We tested whether ERK1/2 pathway is involved in BBR-induced neuroprotective effects in PC12 cells. As shown in Figure 3, phosphorylation of ERK1/2 was gradually increased after the addition of BBR in a concentrationdependent fashion. This data suggested ERK1/2 pathway participated in the protective action of BBR.

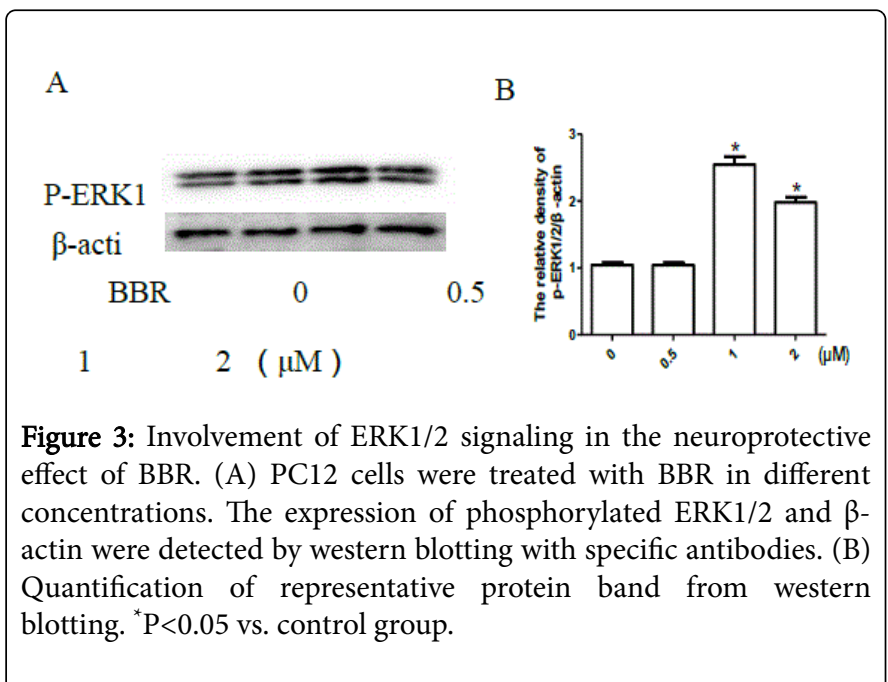

\section{The ERK1/2 pathway inhibitor PD98059 attenuated the protective effects of $B B R$}

To further support the role of ERK1/2 signaling pathway involved in the neuroprotective effect of BBR, PC12 cells were pre-incubated with $25 \mu \mathrm{M}$ PD98059 (a specific inhibitor of MEK which is an upstream kinase of ERK1/2), and then the neuroprotective effect of BBR on $\mathrm{H}_{2} \mathrm{O}_{2}$-induced injury was investigated by MTT assay. As shown in Figure 4, pre-incubation with $\mathrm{PD} 98059$ markedly reduced the neuroprotective effect of $\mathrm{BBR}$ on $\mathrm{H}_{2} \mathrm{O}_{2}$-induced cell viability loss. These results indicated that the neuroprotective effect of BBR was mediated by ERK1/2 pathway.

\section{Discussion}

Numerous scientific reports emphasized that oxidative stress plays a crucial role in the pathophysiology of NDs [29-32]. ROS, caused by oxidative stress, lead to lipid peroxidation as well as protein oxidation, resulting in plasma membrane broken and cross-linking of cytoskeletal biomolecules [33-36]. Antioxidants can reduce or delay oxidation process though preventing the initiation or propagation of oxidizing chain reactions. In this study, neuroprotective effect of $\mathrm{BBR}$ on $\mathrm{H}_{2} \mathrm{O}_{2-}$ induced oxidative damage was investigated. Our results showed that $200 \mu \mathrm{M} \mathrm{H} \mathrm{H}_{2} \mathrm{O}_{2}$ significantly increased the cell apoptosis in PC12 cells, while pre-treatment with $\mathrm{BBR}$ was able to significantly attenuate the cell viability loss induced by $\mathrm{H}_{2} \mathrm{O}_{2}$. Further study displayed that the neuroprotective effect of BBR was mediated by the ERK1/2 pathway. 


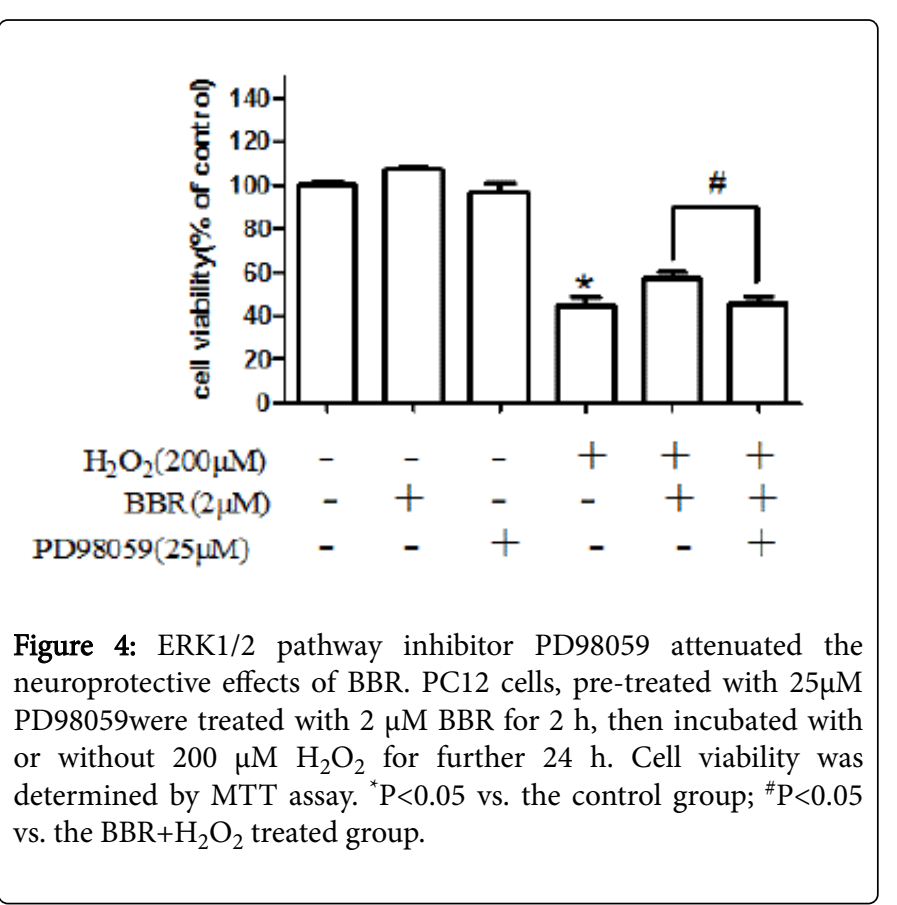

Excessive oxidative stress caused mitochondrial dysfunction and has been proposed to be associated with NDs and brain aging [37]. Therefore, reducing oxidative damage to neuronal cells could be a promising preventive and therapeutic approach [7]. Increasing evidences suggest that many phytochemicals can activate pathways that prevent or reverse oxidative injury. BBR is able to quench superoxide anions and exert radical scavenging activity [38]. In culture cells, BBR was able to inhibit ROS production and prevent generation of superoxide anions caused by NADPH oxidase in the LPS stimulated human monocyte-derived macrophages [39]. It has been reported that BBR inhibited iNOS expression to attenuate NO production. In addition, several reports have shown that BBR induces antioxidant defence by enhancement of the levels of non-enzymatic antioxidants $[15,40]$.

Biologically, ERK1/2 pathway is a key signaling component that plays a crucial role in the regulation of most of cellular processes linked to stimulation such as cell proliferation, cell apoptosis and differentiation. Our results provided mechanistic evidence to support that $\mathrm{BBR}$ protected $\mathrm{PC} 12$ cells from $\mathrm{H}_{2} \mathrm{O}_{2}$-induced oxidative damage via ERK1/2 activation.

In summary, our results demonstrated that $\mathrm{BBR}$ is able to protect PC12 cells from $\mathrm{H}_{2} \mathrm{O}_{2}$-induced oxidative damage and this protective effect is mediated, at least in part by activated ERK1/2 signaling.

\section{Acknowledgements}

This research was financially supported by the National Natural Science Foundation of China (31371088); the Guangdong Provincial Project of Science and Technology (2011B050200005); SRG2015-00004-FHS and MYRG2016-00052-FHS from University of Macau, and the Science and Technology Development Fund (FDCT) of Macao (FDCT 021/2015/A1 and FDCT016/2016/A1).

\section{References}

1. Halliwell B (2006) Oxidative stress and neurodegeneration: where are we now? J Neurochem 97: 1634-1658.

2. Limongi D, Baldelli S (2016) Redox Imbalance and Viral Infections in Neurodegenerative Diseases. Oxid Med Cell Longev pp: 1-13.

3. Jellinger KA (2010) Basic mechanisms of neurodegeneration: a critical update. J Cell Mol Med 14: 457-487.

4. Gandhi S, Abramov AY (2012) Mechanism of oxidative stress in neurodegeneration. Oxid Med Cell Longev pp: 1-11.

5. Barber SC, Mead RJ, Shaw PJ (2006) Oxidative stress in ALS: a mechanism of neurodegeneration and a therapeutic target. Biochim Biophys Acta 1762: 1051-1067.

6. Ballard C, Gauthier S, Corbett A, Brayne C, Aarsland D, et al. (2011) Alzheimer's disease. Lancet 377: 1019-1031.

7. Pérez-Hernández J, Zaldívar-Machorro VJ, Villanueva-Porras D, VegaÁvila E, Chavarría A (2016) A Potential Alternative against Neurodegenerative Diseases: Phytodrugs. Oxid Med Cell Longev pp: 1-19.

8. Ahmed T, Gilani AU, Abdollahi M, Daglia M, Nabavi SF, et al. (2015) Berberine and neurodegeneration: A review of literature. Pharmacol Rep 67: 970-979.

9. Lin MT, Beal MF (2006) Mitochondrial dysfunction and oxidative stress in neurodegenerative diseases. Nature 443: 787-795.

10. Sun B, Sun GB, Xiao J, Chen RC, Wang X, et al. (2012) Isorhamnetin inhibits $\mathrm{H} 2 \mathrm{O} 2$-induced activation of the intrinsic apoptotic pathway in H9c2 cardiomyocytes through scavenging reactive oxygen species and ERK inactivation. J Cell Biochem 113: 473-485.

11. Wakaskar RR, Bathena SP, Tallapaka SB, Ambardekar VV, Gautam NET, et al. (2015) Peripherally cross-linking the shell of core-shell polymer micelles decreases premature release of physically loaded combretastatin A4 in whole blood and increases its mean residence time and subsequent potency against primary murine breast tumors after IV administration. Pharm Res 32: 1028-1044.

12. Ambardekar VV, Wakaskar RR, Sharma B, Bowman J, Vayaboury W, et al. (2013) The efficacy of nuclease-resistant Chol-siRNA in primary breast tumors following complexation with PLL-PEG(5K). Biomaterials 34: 4839-4848.

13. Chen DL, Yang KY (2017) Berberine alleviates oxidative stress in islets of diabetic mice by inhibiting miR-106b expression and up-regulating SIRT1. J Cell Biochem.

14. Kumar A, Ekavali, Chopra K, Mukherjee M, Pottabathini R, et al. (2015) Current knowledge and pharmacological profile of berberine: An update. Eur J Pharmacol 761: 288-297.

15. Spinozzi S, Colliva C, Camborata C, Roberti M, Ianni C, et al. (2014) Berberine and Its Metabolites: Relationship between Physicochemical Properties and Plasma Levels after Administration to Human Subjects. J Nat Prod 77: 766-772.

16. Caliceti C, Rizzo P, Cicero AF (2015) Potential benefits of berberine in the management of perimenopausal syndrome. Oxid Med Cell Longev pp: $1-9$.

17. Liu D, Ke Z, Luo J (2016) Thiamine Deficiency and Neurodegeneration: the Interplay Among Oxidative Stress, Endoplasmic Reticulum Stress, and Autophagy. Mol Neurobiol.

18. Singh AK, Kashyap MP, Tripathi VK, Singh S, Garg G, et al. (2016) Neuroprotection Through Rapamycin-Induced Activation of Autophagy and PI3K/Akt1/mTOR/CREB Signaling Against Amyloid-beta-Induced Oxidative Stress, Synaptic/Neurotransmission Dysfunction, and Neurodegeneration in Adult Rats. Mol Neurobiol.

19. Cai Z, Wang C, Yang W (2016) Role of berberine in Alzheimer's disease. Neuropsychiatr Dis Treat 12: 2509-2520.

20. Zhang C, Li C, Chen S, Li Z, Jia X, et al. (2017) Berberine protects against 6-OHDA-induced neurotoxicity in PC12 cells and zebrafish through hormetic mechanisms involving $\mathrm{PI} 3 \mathrm{~K} / \mathrm{AKT} / \mathrm{Bcl}-2$ and Nrf2/HO-1 pathways. Redox Biol 11: 1-11. 
Citation: Liu L, Zeng Z, Gaur U, Fang J, Little PJ, et al. (2017) Berberine Protects against Hydrogen Peroxide-Induced Oxidative Damage in PC12 Cells through Activation of ERK1/2 Pathway. Clin Exp Pharmacol 7: 236. doi:10.4172/2161-1459.1000236

Page 5 of 5

21. Zheng WH, Fink DW, Guroff G (1996) Role of protein kinase C alpha in nerve growth factor-induced arachidonic acid release from PC12 cells. J Neurochem 66: 1868-1875.

22. Wang H, Zhou X, Huang J, Mu N, Guo Z, et al. (2013) The role of Akt/ FoxO3a in the protective effect of venlafaxine against corticosteroneinduced cell death in PC12 cells. Psychopharmacology (Berl) 228 129-141.

23. Wen Q, Duan X, Liao R, Little P, Gao G, et al. (2011) Characterization of intracellular translocation of Forkhead transcription factor O (FoxO) members induced by NGF in PC12 cells. Neurosci Lett 498: 31-36.

24. Zheng W, Chong CM, Wang H, Zhou X, Zhang L, et al. (2016) Artemisinin conferred ERK mediated neuroprotection to PC12 cells and cortical neurons exposed to sodium nitroprusside-induced oxidative insult. Free Radic Biol Med 97: 158-167.

25. Zeng Z, Wang X, Bhardwaj SK, Zhou X, Little PJ, et al. (2016) The Atypical Antipsychotic Agent, Clozapine, Protects Against Corticosterone-Induced Death of PC12 Cells by Regulating the Akt/ FoxO3a Signaling Pathway. Mol Neurobiol.

26. Chong CM, Zheng W (2016) Artemisinin protects human retinal pigment epithelial cells from hydrogen peroxide-induced oxidative damage through activation of ERK/CREB signaling. Redox Biol 9: 50-56.

27. Song D, Song J, Wang C, Li Y, Dunaief JL (2016) Berberine protects against light-induced photoreceptor degeneration in the mouse retina. Exp Eye Res 145: 1-9.

28. Cui G, Qin X, Zhang Y, Gong Z, Ge B, et al. (2009) Berberine differentially modulates the activities of ERK, p38 MAPK, and JNK to suppress Th17 and Th1 T cell differentiation in type 1 diabetic mice. J Bio Chem 284: 28420-28429.

29. Alinezhad H, Azimi R, Zare M, Ebrahimzadeh MA, Eslami S, et al. (2013) Antioxidant and Antihemolytic Activities of Ethanolic Extract of Flowers, Leaves, and Stems of Hyssopus officinalis L. Var. angustifolius. International J Food Prop 16: 1169-1178.

30. Saeidnia S, Abdollahi M (2013) Toxicological and pharmacological concerns on oxidative stress and related diseases. Toxicol Appl Pharmacol 273: $442-455$.
31. Amin FU, Shah SA, Kim MO (2016) Glycine inhibits ethanol-induced oxidative stress, neuroinflammation and apoptotic neurodegeneration in postnatal rat brain. Neurochem Int 96: 1-12.

32. Barodia SK, Creed RB, Goldberg MS (2016) Parkin and PINK1 functions in oxidative stress and neurodegeneration. Brain Res Bull.

33. Bhattacharjee N, Borah A (2016) Oxidative stress and mitochondrial dysfunction are the underlying events of dopaminergic neurodegeneration in homocysteine rat model of Parkinson's disease. Neurochem Int 101: 48-55.

34. Cacabelos R, Reddy VP, Aliev G (2016) Editorial: Neurodegeneration, Oxidative Stress, Metabolic Syndrome, Drug Design and Development: Clinical Implications. CNS Neurol Disord Drug Targets 15: 126.

35. Calderón Guzmán D, Brizuela NO, Ortíz Herrera M, Hernández García E, Barragán Mejía G, et al. (2016) Effect of cerebrolysin on dopaminergic neurodegeneration of rat with oxidative stress induced by 3nitropropionic acid. Acta Pharm 66: 443-448.

36. Javed H, Azimullah S, Haque ME, Ojha SK (2016) Cannabinoid Type 2 (CB2) Receptors Activation Protects against Oxidative Stress and Neuroinflammation Associated Dopaminergic Neurodegeneration in Rotenone Model of Parkinson's Disease. Front Neurosci 10: 321.

37. Martinez-Vicente M (2017) Neuronal Mitophagy in Neurodegenerative Diseases. Front Mol Neurosci 10: 64

38. Siow YL, Sarna L, Karmin O (2011) Redox regulation in health and disease-Therapeutic potential of berberine. Food Res Int 44: 2409-2417.

39. Sarna LK, Wu N, Hwang SY, Siow YL, O K (2010) Berberine inhibits NADPH oxidase mediated superoxide anion production in macrophages. Can J Physiol Pharmacol 88: 369-378.

40. Shan WJ, Huang L, Zhou Q, Meng FC, Li XS (2011) Synthesis, biological evaluation of 9 -N-substituted berberine derivatives as multi-functional agents of antioxidant, inhibitors of acetylcholinesterase, butyrylcholinesterase and amyloid-beta aggregation. Eur J Med Chem 46: 5885-5893. 